\title{
Web service platform for automatic generation of O/D matrix
}

\author{
Luis Felipe Herrera-Quintero ${ }^{1 *}$, Klaus Banse ${ }^{2}$, Yeimmy Cañon-Lozano ${ }^{1}$, Angie Melo-Castillo \\ and Cesar Augusto Gomez-Perilla'
}

\begin{abstract}
Transportation planning is an important process to support the mobility of the cities, which is a growing problem in several Latin American countries. To face this problem, a normal transportation tool has been used, even until now, and it is known as the origin/destination (O/D) matrix. This matrix allows estimation of the movement of users and future demand on the transportation system and helps improve the planning, travel allocation, and routes of transportation. The novelty of this paper is focused on the design and implementation of a web service platform that can construct automatically the O/D matrix. This platform takes advantage of the service-oriented architecture (SOA) approach and web and mobile applications for the construction of this matrix. In addition, the system is used for public transportation system and takes advantage of Bluetooth technology as a very good approach to construct this matrix.
\end{abstract}

Keywords: Intelligent transportation system; O/D matrix; Web services; SOA; Transportation planning; Bluetooth sensors

\section{Introduction}

Transportation and mobility are fundamental for creation of a high standard of living. The transport system is a key component of infrastructure of cities, providing opportunities for the movement of people and goods, and connections between locations of living, work, and activities [1]. Nowadays, there is a wide range of inventions and cutting edge technology in the sector; however, there exist several problems for resolve like traffic jam, demand supply, and mobility, among others.

The abovementioned problems tend to be mitigated for Intelligent Transport Systems (ITS) which are focused on giving, through synergistic technologies and systems engineering, a great set of solutions for the transport sector $[2,3]$. In this context, many ITS solutions help not only mobility of the cities but also several different areas associated with a normal operation of the cities. For instance, one of the transportation fields which benefited from ITS solutions is public transportation, especially mass transit systems, usually deployed in Latin America. In fact, this

\footnotetext{
* Correspondence: Ifherrera@ucatolica.edu.co

${ }^{1}$ Computer Science Engineering, Catholic University of Colombia, Bogotá, D.C, Colombia

Full list of author information is available at the end of the article
}

kind of transportation takes advantage of several tools in order to be planned. In this context, a common transportation tool called origin/destination (O/D) matrix is used for bringing information about route planning, reducing costs, improving service quality, reducing travel times, and improving infrastructure [4]. In this way, several different O/D trip matrices are done in order to represent the number of users with similar travel characteristics moving between zone pairs of the transportation network, and it is worth noting that reference period is a fundamental input for most transportation planning and design problems [4]. Currently, the generation of these kinds of matrices is performed manually in most Latin American countries; it means that there are people deployed over the transportation network and they must take data in order to build it. However, technology advances have allowed the creation of several sensors that can be used for gathering data, in fact, for this approach, that is, for construction of O/D matrices. For instance, in Bluetooth technology [5], a wireless communication technology is used, among others, for it, but this kind of sensors does not have systems that can work with new business approaches. In this context, in the field of the ITS solutions, new approaches based on service-oriented architecture 
(SOA) have been used. For this reason, a great challenge of ITS applications is to integrate these approaches in several ITS solutions [6], even e-safety. SOA is a collection of self-contained services (system functions) that communicate with each other over specified interfaces [7]. From a business perspective, it is a style of multi-tier computing that helps organizations share logic and data among multiple applications and usage modes. In this context, the SOA approach was used for designing and implementing a novelty platform that can construct automatically the $\mathrm{O} / \mathrm{D}$ matrix. It is worth noting that this research work takes as a base a previous work [8]. However, this new paper is focused on creation, design, and implementation of web service platform based on SOA, which can be used for construction of the O/D matrix for mass transportation systems (public transportation system), and in turn, it takes advantage of Bluetooth technology as a very good communication approach to construct this matrix. The platform is made up of an application web, an application mobile, and a simulator of frames; all of them work together for constructing and giving information to their users about the O/D matrix, in order to support the route planning, check the status of a service station for a specific time, etc.

The rest of this paper is organized as follows. Section 2 describes the contextualization and related work. Section 3 proposed the platform architecture. Section 4 is focused on ITS applications developed using a SOA paradigm. Section 5 describes a test done with Bluetooth sensors and the results obtained by software. Finally, Section 6 presents the conclusions and the future work.

\section{Contextualization and related work}

In the world, where cities and socioeconomic characteristics change, the cities' dynamism depends on a great part on the transportation sector. Governments take this sector as a solid stone to develop their economies and organize strategically the operation of the cities. In light of this, the public transportation is a key and a transversal component that helps citizens to organize how they move over the city. Therefore, buses represent an important part of the mobility [8].

In many Latin American cities, the operation of bus services has been carried out by private companies which apply partially regulated fares and routes, weak management strategies, and transportation planning, creating a poor quality of service. In fact, the bus rapid transit (BRT) in response to dysfunctional and inefficient transport conditions, low quality of service, and poor environmental conditions and road safety was created. Nowadays, there are many successful cases of implementation of BRT, such as VIVA in Toronto and Ontario, Optibus in Leon (Mexico), Transmilenio in Bogotá (Colombia), and Metro Via in Guayaquil (Ecuador), among others $[9,10]$.
A BRT plan should be developed as an integrated system that adapts attributes of rail transit, focusing on major markets, emphasizing speed and reliability, taking advantage of incremental development, and establishing complementary transit-first policies. Other system attributes that are equally important include the times during which service is available, frequency/headways, walking distances, waiting times, transfers, in-vehicle time, a cleaning and appealing image, and fare collection strategies. The elimination or reduction of system features to cut costs should be avoided [11]. Hence, it is very important to have a good transportation planning.

In transportation planning, deploying BRTs is a key factor over the cities, but to do this in an appropriate way, it is important to take advantage of the O/D matrix that allows estimation of the movement of users and future demand on the transport system, and improvement in the planning, travel allocation, and routes of transportation. Normally, this matrix is estimated through math models or using a probabilistic way, by means of people deployed over the transportation infrastructures who take data from buses or freight trucks (road transportation); nevertheless, this fact causes many errors.

However, new ITS approaches based on Bluetooth technology have begun to be used in order to support the generation of the O/D matrix, but focused on determining how a car is moving through the transportation network. Now, our novelty consists of determining how people are moving through the public transportation network. To do this, we focused on deploying Bluetooth sensors throughout the transportation network in order to receive signals from devices equipped with this technology. It is important to highlight that in Latin America, many people have devices equipped with Bluetooth technology and it is normally found over mobile phones. In addition, according to the World Bank, on average, in 2011, there are 107 mobile phones per 100 people in Latin America [12]; this statistics allows the implementation of our proposal which is reliable, because the sensors would capture at least $5 \%$ of total traffic in the lane.

On the other hand, it is worth noting that there is a large number of ITS technologies that can support the generation of $\mathrm{O} / \mathrm{D}$ matrix and their platforms are made up of several technologies. This means that their integration is tightly coupled. For this reason, in other domains, such as e-business, manufacturing, and automotive industry, the service-oriented architecture (SOA) paradigm has been proposed as the most appropriate solution for solving problems in dynamic and heterogeneous technology environments. In fact, many ITS applications have begun to use SOA approaches such as $[13,14]$; even the ISO Technical Committee (TC 204) has recently worked on an SOA for the realization of interoperable ITS (ISO 24097). 


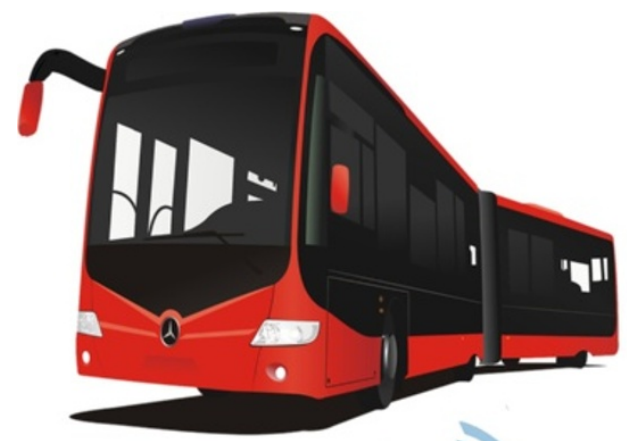

Sitio 1
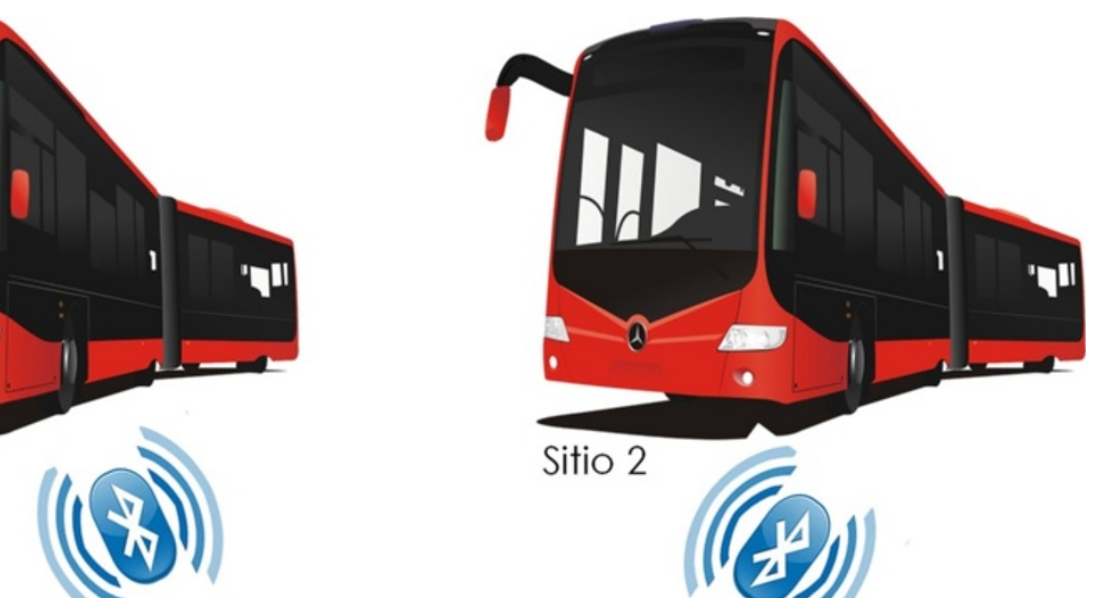

Sitio 2

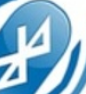

Sensor Beta

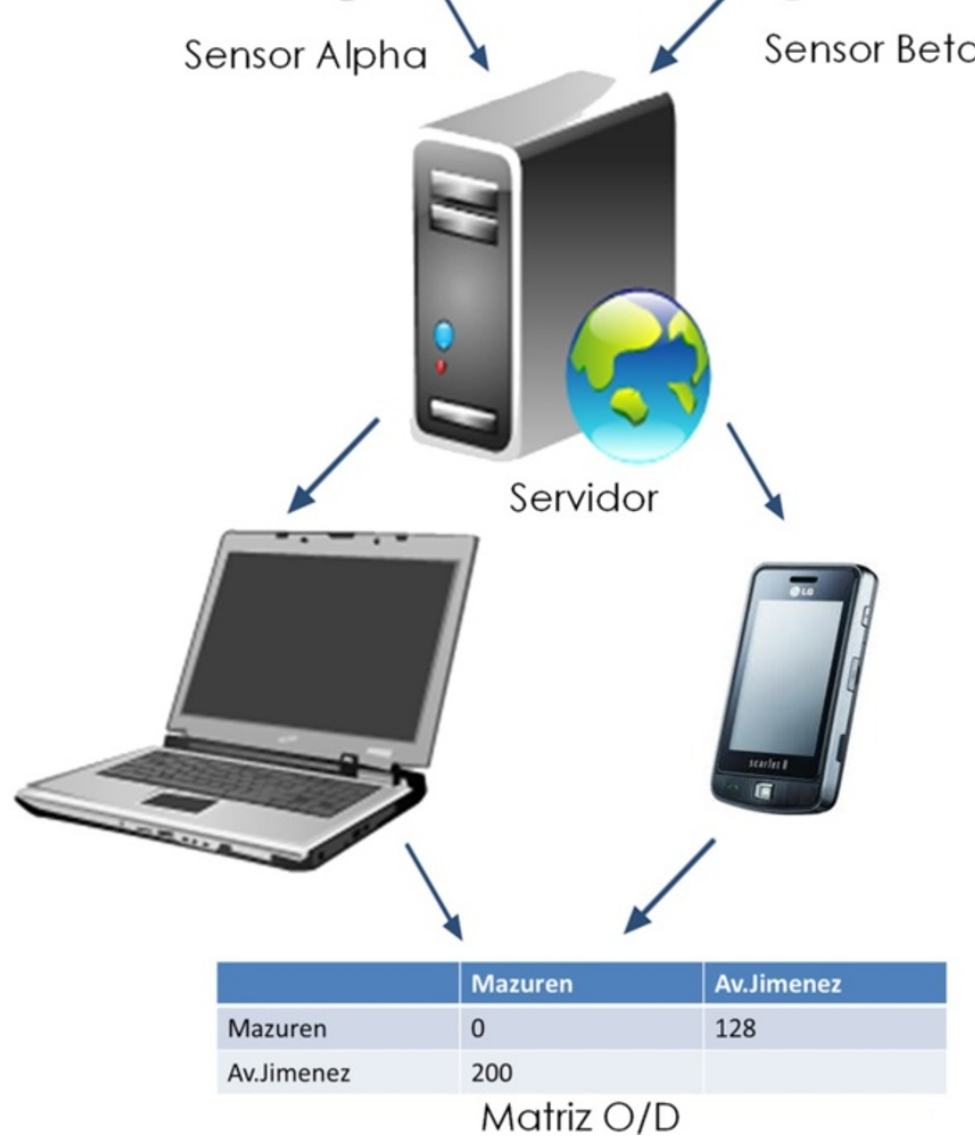

Figure 1 ITS scenario for automatic generation of OD matrix. 
In light of this, our proposal takes advantages of both ITS technologies (Bluetooth sensors) and SOA paradigm in order to determine how people are moving through the public transportation network. Our novelty consist of using mobile phones equipped with Bluetooth technology to detect these signals to offer a dynamic way for $\mathrm{O} / \mathrm{D}$ matrix construction and layout in a web service platform. This means that we can give a great solution to support the organization and planning for public transportation systems in Latin America. In addition, with the design and implementation of a web service platform based on SOA paradigm, it can give information about the O/D matrix in any moment, allowing and helping governments to make decisions about a new way for transportation planning using advanced ITS application that works from mobile devices and traffic centers.

\section{Proposal}

\subsection{Description}

Transportation planning plays a fundamental role in the state, region, or community's vision for its future. It includes an evaluation process that encompasses diverse viewpoints and the collaborative participation of relevant transportation-related agencies and organizations. This

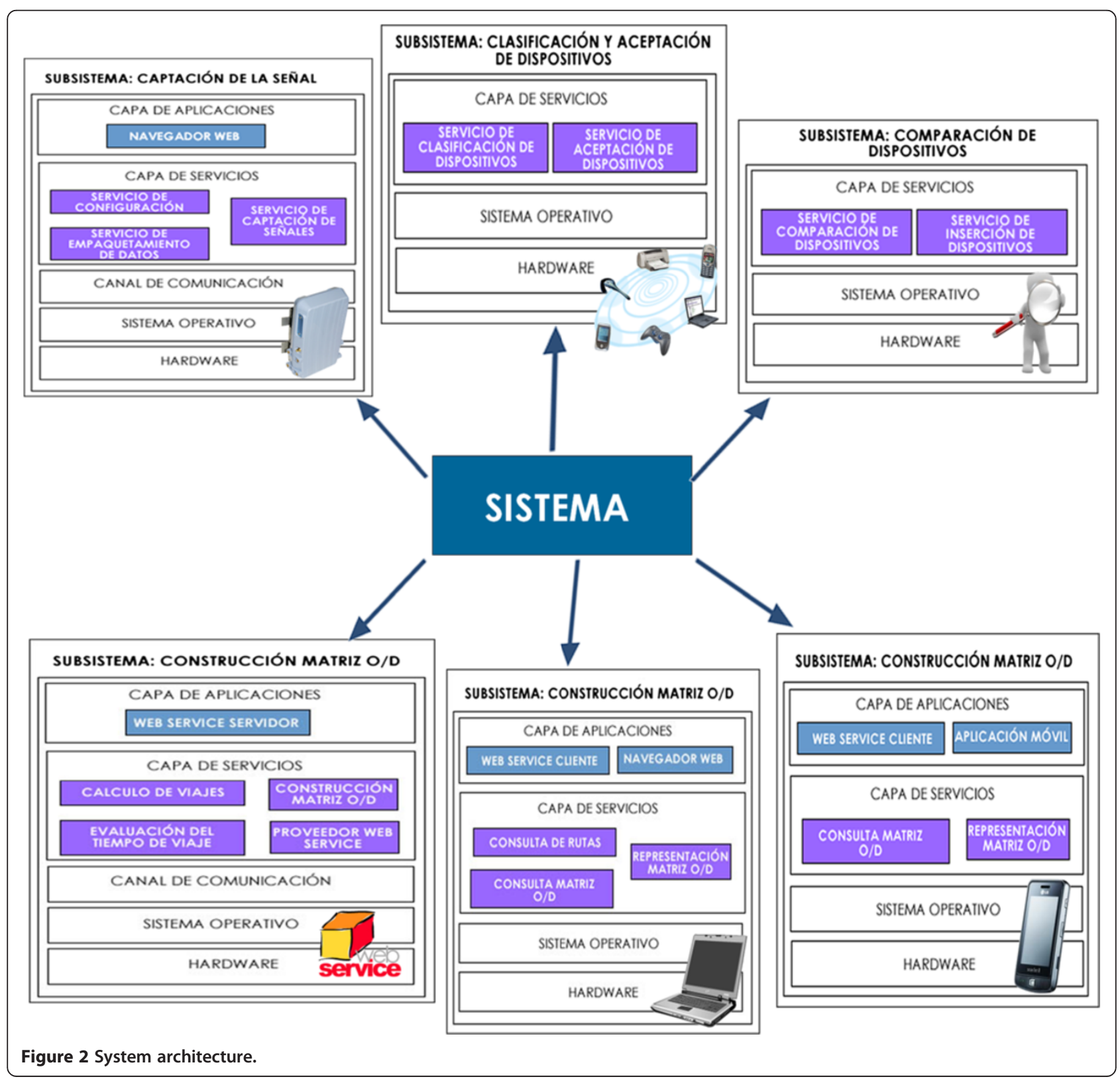


Table 1 Loose coupling by means of an SOA

\begin{tabular}{cccc}
\hline $\begin{array}{c}\text { Kinds of ITS } \\
\text { services }\end{array}$ & $\begin{array}{c}\text { Integration and } \\
\text { decoupling } \\
\text { mechanism }\end{array}$ & $\begin{array}{c}\text { ITS service } \\
\text { provider }\end{array}$ & $\begin{array}{c}\text { ITS } \\
\text { consumer }\end{array}$ \\
\hline $\begin{array}{c}\text { Authentication } \\
\text { service }\end{array}$ & $\begin{array}{c}\text { SOAP (UDDI) } \\
\text { Services } \\
\text { Catalogue }\end{array}$ & $\begin{array}{c}\text { Application } \\
\text { servers (BL) }\end{array}$ & $\begin{array}{c}\text { Application } \\
\text { servers (UL) }\end{array}$ \\
$\begin{array}{c}\text { Registry and } \\
\text { discovery services }\end{array}$ & SOAP (UDDI) & Application & Application \\
for the build O/D matrix* & Services & servers (CTL) & servers (UL) \\
& Satalogue & & \\
Consult services & Services & Application & Application \\
& servers (BL) & servers (UL)
\end{tabular}

*Internal services; ML $\rightarrow$ Monitoring level; $\mathrm{BL} \rightarrow$ Business level; UL $\rightarrow$ User level; CTL $\rightarrow$ Communication Transverse Level; $\mathrm{XX} \rightarrow$ can be WSN, VANET, etc.

evaluation process needs enough information such as the number of people who move from one place to another and demand growth in peak hours and travel times.

To contribute to transportation planning and analyze the mobility in a massive transport system, we developed a web service platform focused on the automatic generation of $\mathrm{O} / \mathrm{D}$ matrix through the signals received by two sensors that measure Bluetooth signals. Our proposal was explained in a previous study [7], but mainly, our system has servers that receive all data frames obtained by each sensor; then, the system processes the received information to make the O/D matrix using an algorithm based on some filters and finally lays out the $\mathrm{O} / \mathrm{D}$ matrix in the web service platform to allow people to access to this data from several places and devices (see Figure 1).

The data captured, processed, and represented in O/D matrix contributes to transport planning, specifically in the creation of new routes and the number of buses that are sent over the routes and feeder routes. Also, this information allows defining the dimensions of the stations, and the service quality increases.

\subsection{System architecture}

The system architecture is made up of four subsystems (see Figure 2) described as follows: uptake signal, device classification and acceptance, device comparison, and O/D matrix construction.

The first subsystem is focused on the uptake signal, and it is filtered by a Bluetooth sensor, which is responsible for capturing signals around the sensor. The second subsystem has, as principal aim, to analyze the kind of user device and decide which devices will be accepted by the system. The third subsystem compares the results of the analysis of the devices and eliminates duplicate records in a time range, and the last subsystem gives the results of an $\mathrm{O} / \mathrm{D}$ matrix from a specific date and time; this is from the web service platform.

As we mentioned before, our proposal takes advantage of the SOA paradigm and we use loose coupling schemes for construction of the O/D matrix using the data gathered. To implement our ITS solution, a web service technology has been used since it is a powerful way to integrate heterogeneous systems. Our solution takes into account three states for an SOA solution, namely, publication, discovery, and consumption.

First, the publication process is carried out by means of a web service that uses a SOAP (Simple Object Access Protocol) message to put in a register server such as UDDI (Universal Description Discovery and Integration - directory of web service interfaces described by WSDL - Web Services Description Language) services that will be published, such as user authentication service, build O/D matrix service, and consult O/D matrix service.

The first service authenticates the user who wants to enter the system from a login and password defined in the database to prevent misuse of the service. The second service builds the O/D matrix from several initial filters. Such filters are applied into frames provided by the sensor, for instance, eliminating redundant data and bad data. These filters work according to flow estimation, which is based on three parameters given by the user (path, start date, and final date). The last service allows users to consult the matrix $\mathrm{O} / \mathrm{D}$ from the above parameters from a mobile device, a client application, or a web application.

As regards the discovery process, several mobile devices or even a PC desktop can discover the services, which can be used to know the O/D matrix. UDDI offers users a unified and systematic way to find service providers through a centralized registry of services, and supports this process. Finally, the consumption process is achieved when mobile devices use the mentioned web services; it means that either by web application or mobile application, the services can be consumed. We have three kinds of services that are used in ITS (see Table 1).

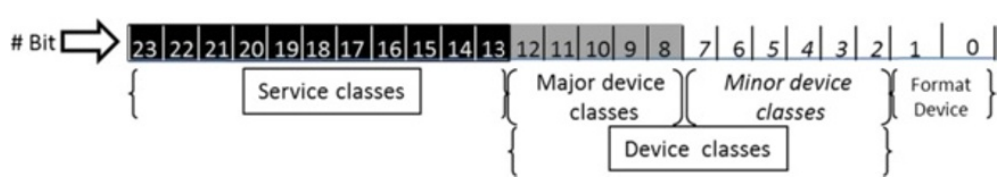

Figure 3 Class of device/service (CoD). 
However, in future work, we will work with WSSecurity, which is a standard that states a strategy and specifications to bring different security technologies together. The WS-Security specification defines how XML Digital Signatures and XML Encryption may be used with SOAP messages.

\subsection{Algorithms}

The implemented system uses several algorithms based on filters and the Bluetooth standard that classify the devices and services. Hence, it is worth understanding how Bluetooth technology does it.

Bluetooth standard defines a baseband associated with DIACs (the General- and Device-Specific Inquiry Access Codes) which is the first level of filtering to find Bluetooth devices and services [15]. Summarizing, each Bluetooth device incorporates a hexadecimal number of five digits that represent the Inquiry Access Code (see Figure 3).

The last 11 bits identify the services that endure the devices and have 7 categories for this [15]. The next 11 bits identify the nature of the device specifying the generic type of device. In fact, the algorithm takes in to account this standard to identify and classify the possible devices that Latin American people have with themselves.

Using the information mentioned before, the subsystems implement an algorithm and support the generation of the O/D matrix. The first one uses a filter to accept devices based on a list. This list is based on a major device class of the standard mentioned; we consider several devices used for the public transportation user. From the list of devices included, we consider some [7] like phone, computer, and toy. As a consequence, the filter rejects all frames and data related with the devices that contain a major class of device that is not on the proposed list (see Figure 4).

Second, the subsystem of device comparison implemented an algorithm that compares all the times that the device was captured by the sensor and stores only the record with the best power. The system has an average trip time by route. The data or frame with the best power is taken by scales divided in this time; that means if the device is in two scales, it is taken like two different devices, and the system takes the best power in the scale for each respective device, in this case for two devices.

Third, the subsystem verifies that the device is captured for the two sensors in the average trip time specified for this route.

Summarizing, the subsystem O/D matrix to achieve automatic generation of the $\mathrm{O} / \mathrm{D}$ matrix considers the following procedure: first, evaluating the devices captured by at least two sensors; second, comparing devices captured with the device class list mentioned before; and finally,

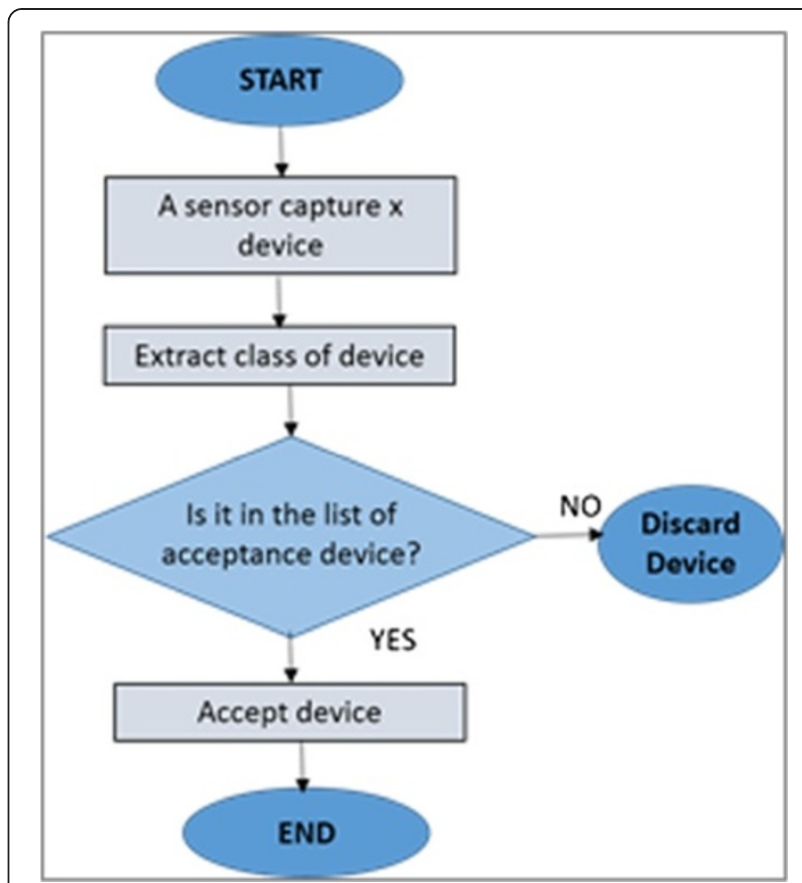

Figure 4 Filter algorithm.

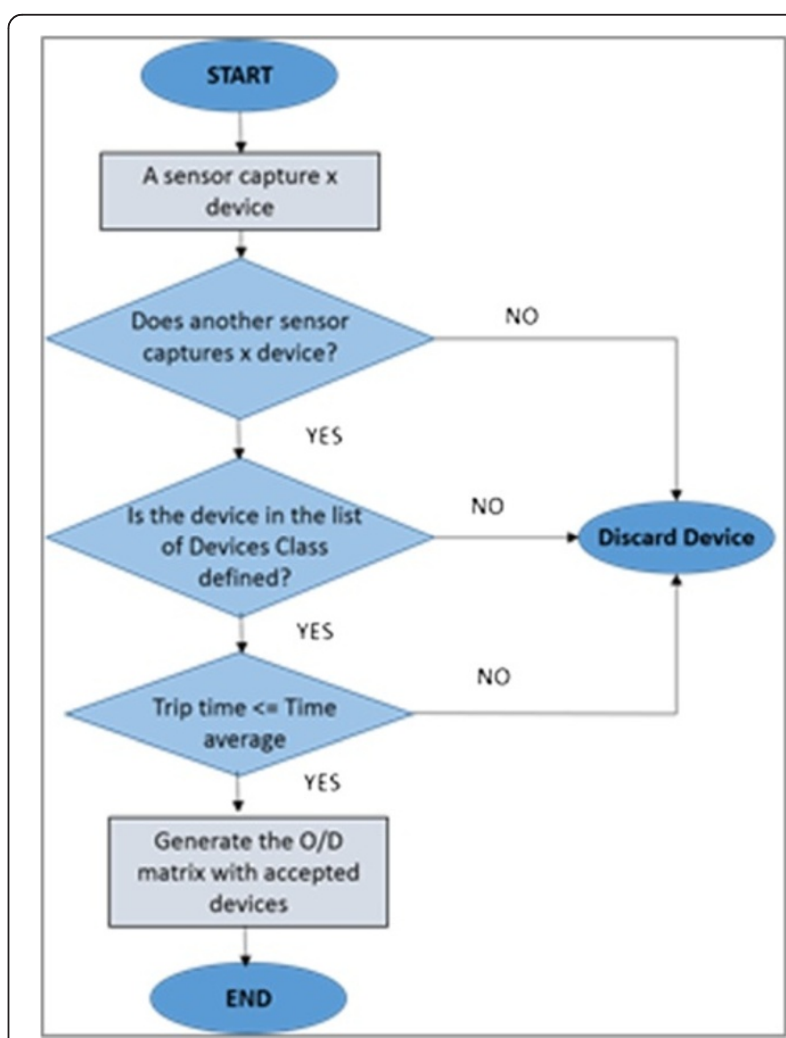

Figure 5 Generation of O/D matrix algorithm. 


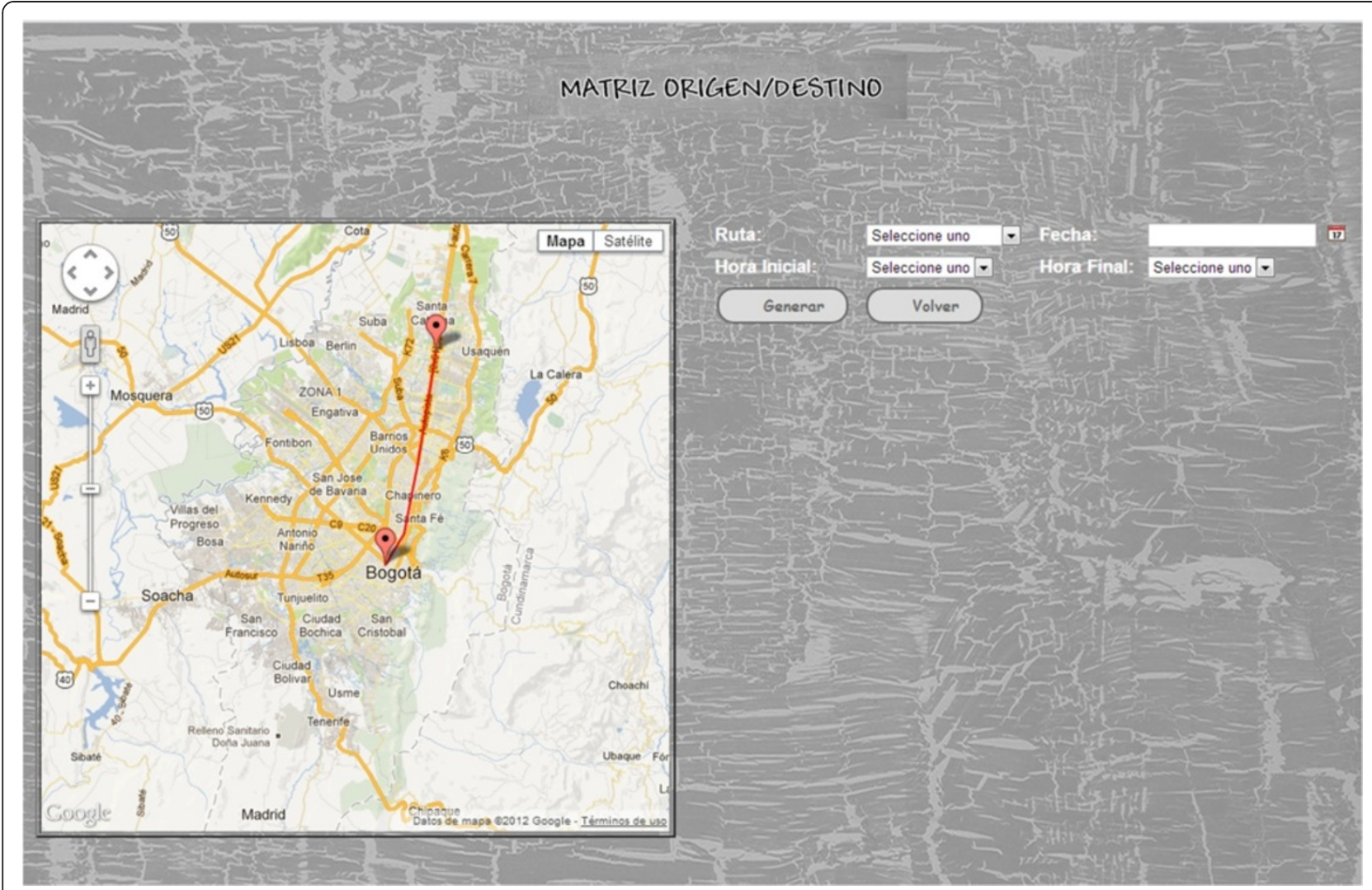

Figure 6 Web application.

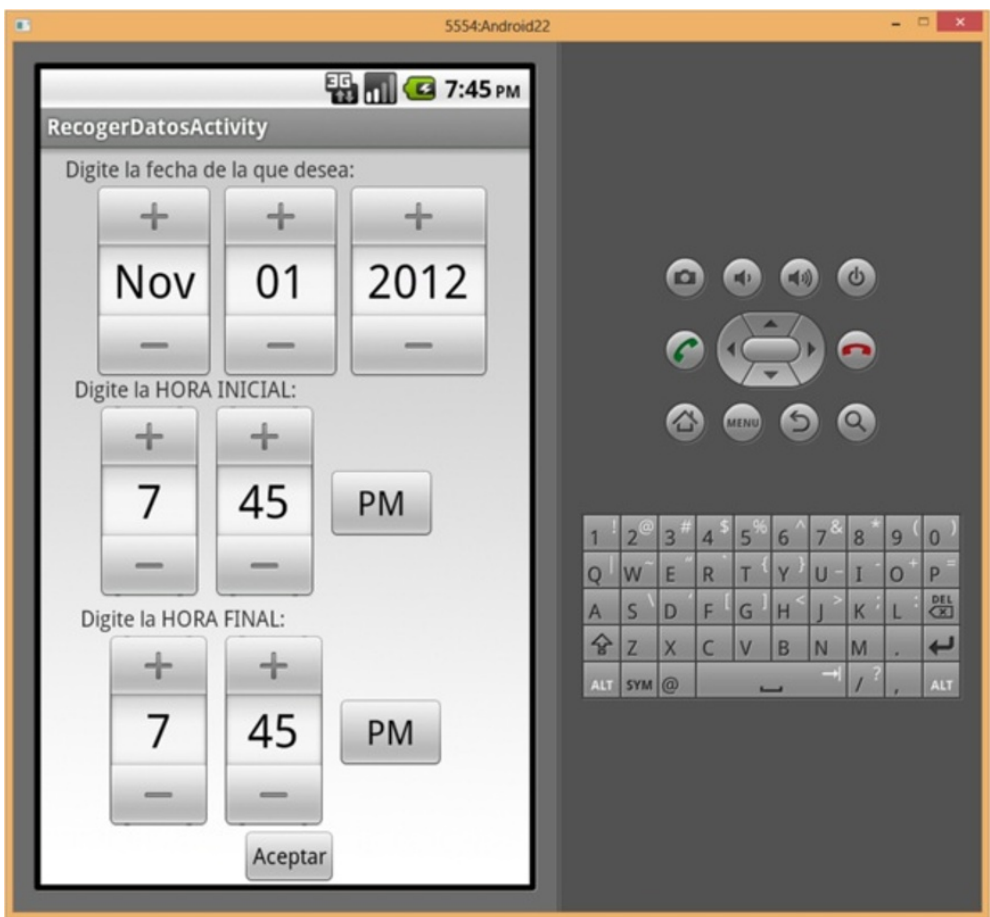




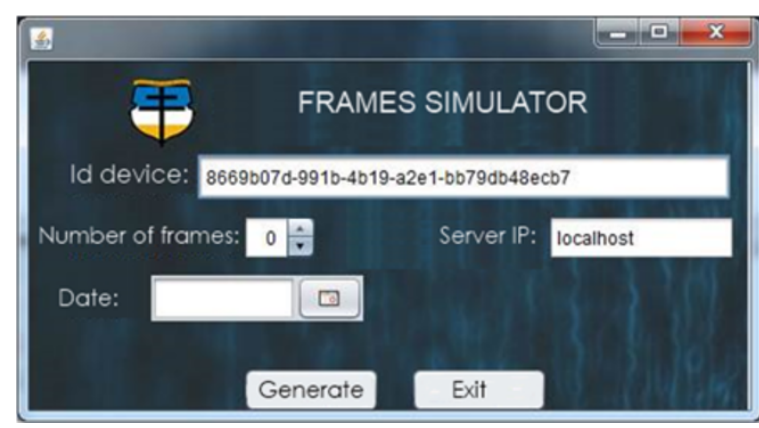

Figure 8 Frame simulator application.

rejecting the devices where trip time exceeds the average time (see Figure 5).

\subsection{Sensors and frames}

To design and implement a web service platform, we have used Bluetooth sensors which give us a data schema with the most important information about devices. To generate the O/D matrix, the following are considered: the captured devices, the time in seconds to which the Bluetooth scan was recorded, the MAC encrypted devices, and the kind of device.

In this project, we test two different sensors: The first one was provided by Trafficnow Company [16] whose optimized antenna allows receiving of Bluetooth signal from other devices and has an efficient scan process to $270 \mathrm{~m}$ before the place where the sensor is installed. The second one was proportioned by Acyclica company [17]. It is similar to the Trafficnow sensor, but the great difference is that the Acyclica sensor captures both Bluetooth and Wi-Fi signals and this fact opens the possibility to acquire the Wi-Fi signals in the same proposal.

In addition, to each of the sensors, it is accurate to have a voltage source set on average at $24 \mathrm{~V}$, and to configure them, it is possible to use a GPRS configuration or a network cable.

\section{ITS applications}

In order to achieve our goal, three ITS applications that work over a web service scheme have been developed. The first one (Figure 6) is focused on web application,

Table 2 Devices with Bluetooth

\begin{tabular}{lcc}
\hline Device & Name device & Mac address \\
\hline PDA & Pocket PC & 08:00:28:d6:07:a4 \\
Cell phone & Motorola 115 & 00:0d:92:c5:5f:7f \\
Cell phone & Nokia N8 & $04: 5 a: 95: 25: 30: 5 a$ \\
Laptop & Samsung & $88-53-2 e-b 9-96-9 a$ \\
Cell phone & Samsung GT S5260 & $84: 25: D B: D A: D 2: 5 ~ F$ \\
\hline
\end{tabular}

which offers the consulting of O/D matrix service through the Internet; this is very usable and incorporates security through user authentication. When an authentication process has been successful, the user (traffic center) can consult the roadmap or O/D matrix. If the user chooses the roadmap, Bluetooth sensors will be deployed on the city map and it will be possible to generate routes and pictures from several places.

The second one is mobile application that works under the Android platform (Figure 7). This application allows consulting of the $\mathrm{O} / \mathrm{D}$ matrix for a range of specific dates and times. Likewise, a web service scheme based on the SOA paradigm was used in order to exchange data between server application and mobile application. Therefore, the changes over time in one should not affect the other; thus, it is a decoupled architecture.

Finally, the third application related to a frame simulator was designed and implemented. This application was developed for testing the database deployed, the filtering algorithms, and the programs that generate automatically the O/D matrix. The simulator is made up of a server component and a client component; these communicate through sockets (see Figure 8).

The application works with the following fields: requires the ID device Origin \& Destination to represent the Bluetooth sensors and, in addition, indicates the number of devices that want to be generated as well as the repetition rate in the target sensor, the date of generation of the data, and the time duration of capture.

\section{Case study}

For the case study, we used two Bluetooth sensors and several devices (represented in Table 2) which will be captured by the sensors.

The sensors were activated for $15 \mathrm{~min}$. For the test, we have created a denotation for the sensors; the first one is

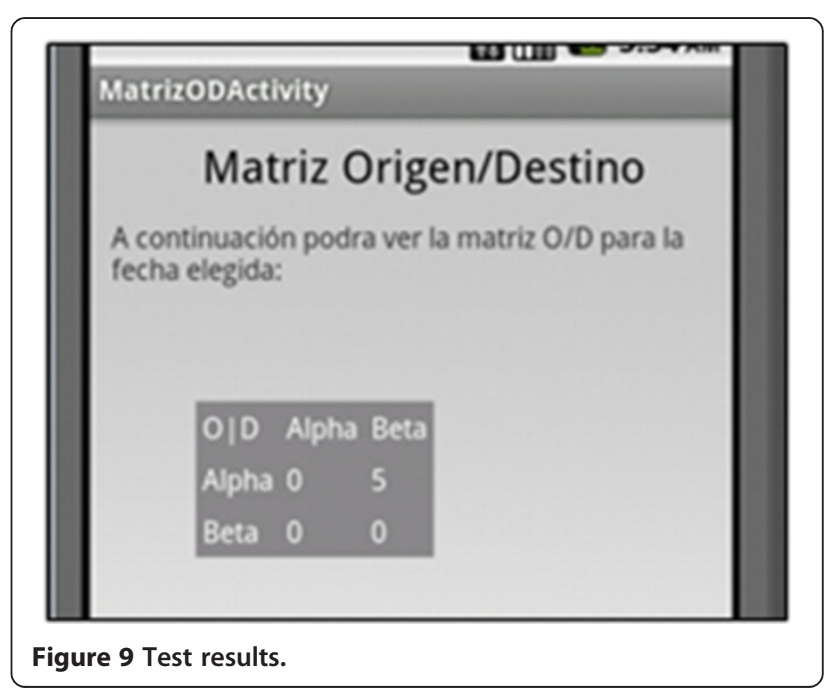




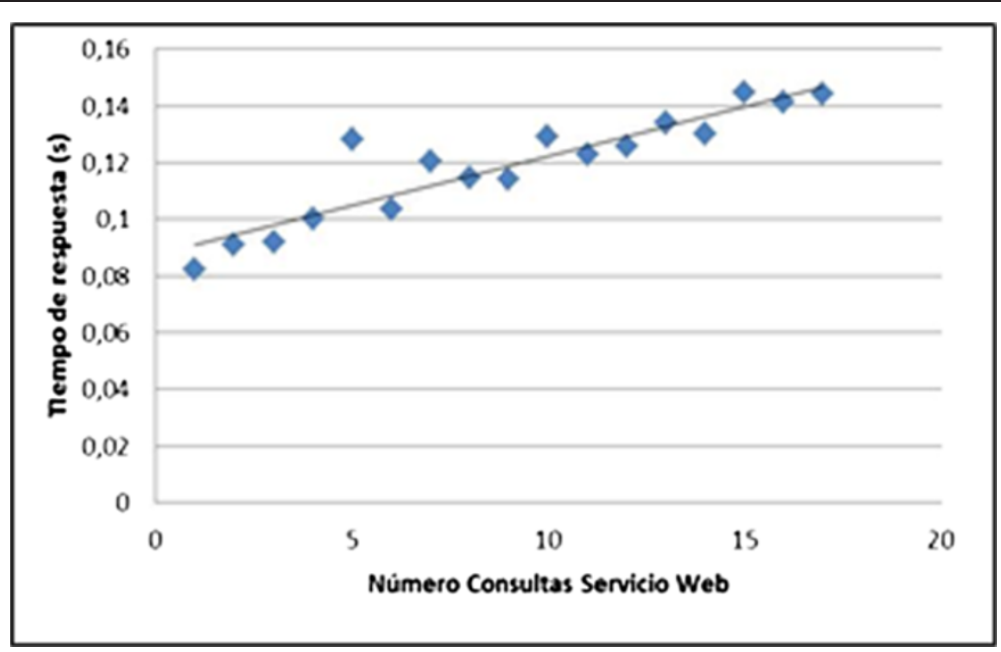

Figure 10 Graphical of response times of web application.

called the alpha sensor which is the origin, and the second one is called the beta sensor which is the destination. The capture range for the device by the sensors is 15 min between them. We performed several tests during different times, but we present just one of them. In this context and according to devices that were used, the result of the matrix in a single sense (alpha-beta) is presented in Figure 9.

Regarding the web application, the response time for 17 simultaneous users was tested, looking at a range between 0.082 and $0.147 \mathrm{~s}$ (see Figure 10). Furthermore, Figure 11 shows the classification of devices into mobile devices and others; since the consistency of the matrix relies on mobile devices, a further study will be made when the sensors will be installed in the public transportation system.

$x$ The previous article lists all the filters used to generate the O/D matrix [7]. These filters cannot determine whether a user carries some devices with Bluetooth technology simultaneously or only one device. This will be considering different users, but this topic is under study.

In the test, the alpha sensor captured 1,017 records; these form part of multiple captures by the sensor of about 76 devices, where $74 \%$ of the found devices were mobile phones, including smart phones; the other $26 \%$ includes different kinds of devices like wearable headphones, handheld PC/PDA, hands-free, desktop workstation, and cordless phone. Furthermore, the sensor found two devices uncategorized, which means that the codes of these devices are not specified (see Figures 12). On the other hand, the beta sensor captured 890 records of 30 devices found, where $83 \%$ were mobile phones and the remaining $17 \%$ were laptops.

Regarding the previous outcomes about the number of cell phones captured by each sensor, it is important to

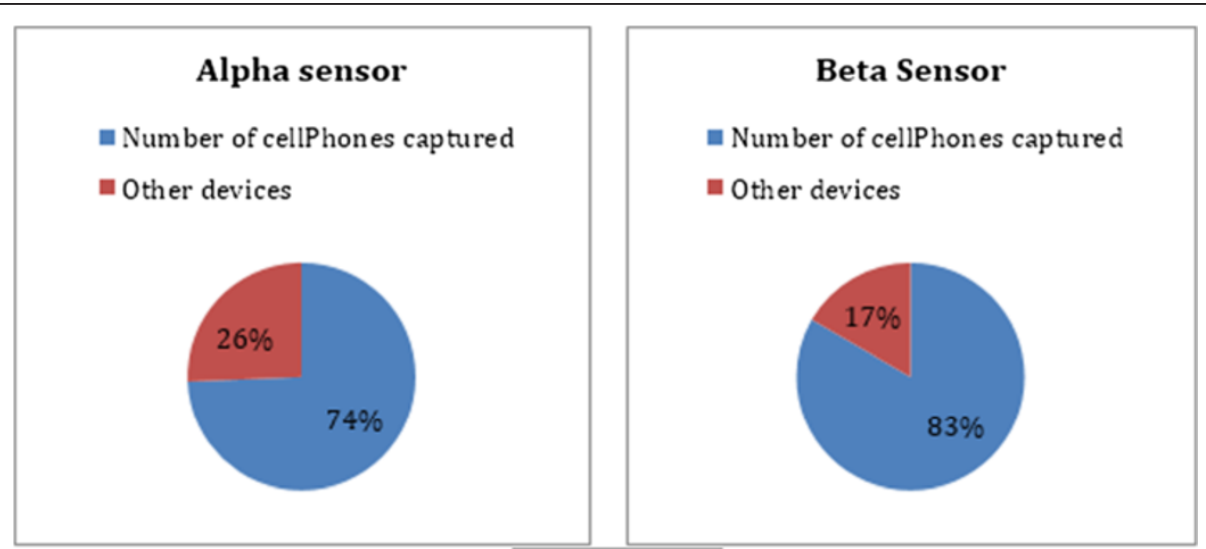

Figure 11 Number of devices captured by sensors. 


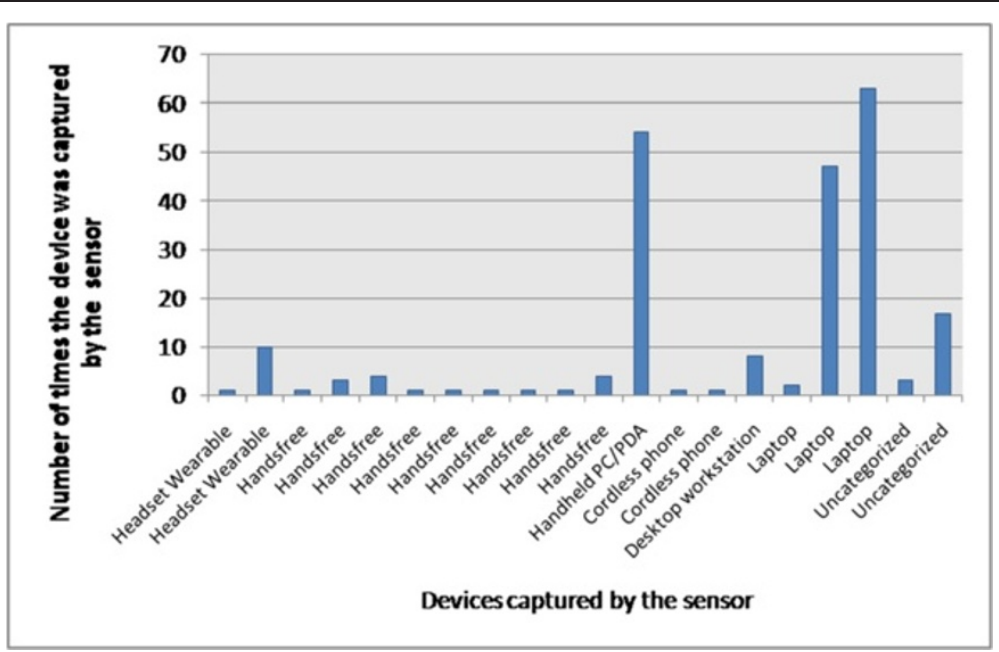

Figure 12 Type of devices captured by alpha sensor.

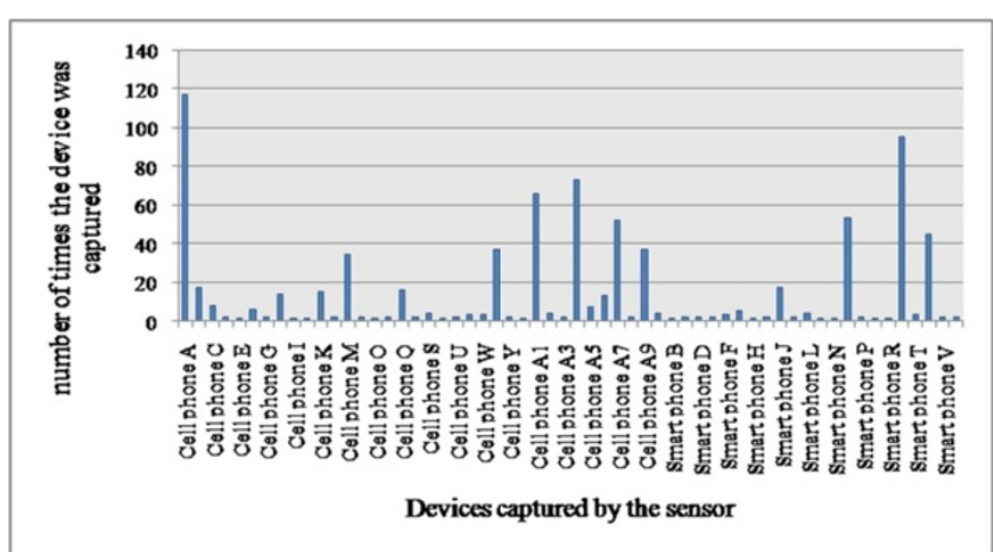

Figure 13 Number of times the alpha sensor captured the same cell phones.

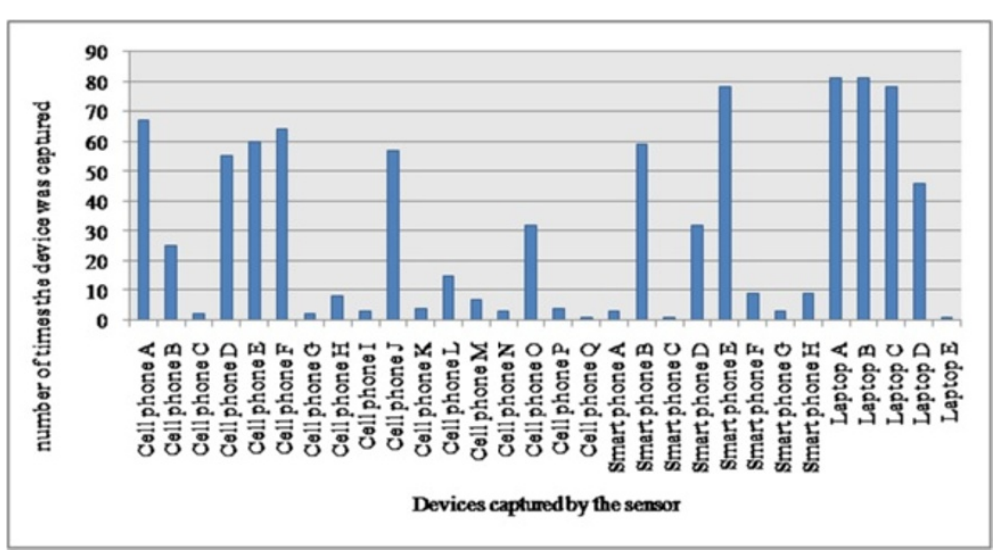

Figure 14 Number of times the beta sensor captured the same cell phones. 
highlight that the outcomes show different kinds of cell phones, and each one was captured several times. The time that each cell phone was captured depends on the distance between the sensor and device (it was not captured when it was out of the sensor range visibility) and the turning on of the Bluetooth function. In the test for the alpha sensor (see Figure 13) we kept cell phone A within the sensor range visibility and with the Bluetooth function turned on; therefore, the sensor captured it 118 times, while the other devices were appearing and disappearing in the data. On the other hand, in the test for the beta sensor (see Figure 14), the Bluetooth function was turned off and after a while, the sensor captured it 67 times, less than that in the last test.

\section{Conclusions}

The article presented a new platform based on web services in order to generate automatically the $\mathrm{O} / \mathrm{D}$ matrix for users of public transport systems. The proposed solution is highly innovative because it involves several technologies of great penetration in any country. In addition, this platform uses a SOA approach to achieve loose coupling between ITS technologies that use this kind of platform. Connecting the mobile phone with Bluetooth technology and, in turn, using and deploying a novelty approach to determine the O/D matrix and lay it out above a web service platform allow to consult the O/D matrix from several places and devices and also give new solutions for transportation planning and its operation of public transport, and it will even allow to reduce their fares.

Currently, we are working on the project, and in a future work, we will work to incorporate WS-Security to apply security to our web services. Furthermore, a group of students of the Catholic University of Colombia is developing a project based on this work to improve the data storage using NoSQL approaches. Moreover, we are implementing our own sensors for the system; we using a credit card-sized tool called Raspberry [18].

\section{Competing interests}

The authors declare that they have no competing interests.

\section{Acknowledgements}

We acknowledge the Catholic University of Colombia, Trafficnow Company, Acyclica, and ITS Colombia for their contribution to the implementation and experiments

\section{Author details \\ 'Computer Science Engineering, Catholic University of Colombia, Bogotá, D.C, Colombia. ${ }^{2}$ TTS Colombia, Bogotá, D.C, Colombia.}

Received: 21 February 2014 Accepted: 24 June 2014

Published: 12 July 2014

\section{References}

1. Prattley, Gary/Western Australian Planning Commission, Guidelines for preparation of integrated transport plans", p. 16. http://www.planning.wa.gov. au/dop_pub_pdf/guidelines_integrated_transport_whole.pdf. Accessed 09 August 2013

2. B Morris, IEEE ITS Society Web Page, http://sites.ieee.org/itss/. Accessed 10 September 2013

3. T Yokota, H Ishida, K Kato, ITS toolkit for road transport in countries with developing and transitional economies. Transp. Res. Rec.: J. Transp. Res. Board 1, 6 (2004). doi:10.3141/1886-01

4. E Cascetta, MN Postorino, Fixed point approaches to the estimation of O/D matrices using traffic counts on congested networks. Transp. Sci. Informs. Transp. Sci. 35(2), 134-147 (2001). doi:10.1287/trsc.35.2.134.10138

5. Bluetooth web page, Bluetooth basics, http://www.bluetooth.com/Pages/ Basics.aspx. Accessed 09 September 2013

6. M Papazoglou, P Traverso, S Dustdar, F Leyman, Service-oriented computing: state of the art and research challenges. IEEE Comput. 40, 35-40 (2007). doi:10.1109/MC.2007.400

7. C Yeimmy, M Angie, B Klaus, $\mathrm{H}$ Luis, Automatic generation of O/D matrix for mass transportation systems using an ITS approach. Proc. IEEE Symp. Colomb. Intell. Transp. Syst. (CITSS) IEEE Press Agu 1-6 (2012). 10.1109/CITSS.2012.6336681

8. H Dario, Contribuciones de Transmilenio a los sistemas de Transporte Masivo de Alta Capacidad en Buses (BRT), http://www.ttdp.org. Accessed 09 September 2013

9. H Levinson, S Zimmerman, J Clinger, J Gast, E Bruhn, Transportation Research Board. Bus Rapid Transit 2, 1-149 (2003). http://onlinepubs.trb.org/onlinepubs/ tcrp/tcrp_rpt_90v2.pdf. Accessed 04 May 2013

10. J Barcelò, L Montero, L Marques, C Carmona, Travel time forecasting dynamic origin-destination estimation for freeways based on Bluetooth traffic. Transp. Res. Rec. 2175, 19-27 (2010). http://dx.doi.org/10.3141/217503, http://futur.upc.edu/4500801. Accessed 04 May 2013

11. Transportation Planning Capacity Building Program, The transportation planning process key issues, http://www.planning.dot.gov/documents/ briefingbook/bbook_07.pdf. Accessed 04 May 2013

12. World Bank, World development indicators 2013, 2013. http://data.worldbank.org. Accessed 04 May 2013

13. X Tao, C Jiang, Y Han, Applying SOA to Intelligent Transportation System (Proc. IEEE Symp. International Conference on Services Computing (SCC'05), Orlando, Florida, USA, 2005), pp. 101-106. doi:10.1109/SCC.2005.28

14. W Shi, W Jian, L Ying, K Li, Intelligent transportation information sharing and service integration in semantic grid environment (Proc. IEEE Symp, International Conference on Web Intelligence (WI 2006 Main Conference Proceedings), Hong Kong, China, 2006), pp. 174-180. doi:10.1109/WI.2006.101

15. Bluetooth, Bluetooth baseband, https:/www.bluetooth.org. Accessed 04 May 2013

16. A Reig, Trafficnow, Bluetooth Sensor web page, http://www.deepbluesensor.com/

17. D Benhammou, Bluetooths and Wifi sensors web page Acyclica, http://www.acyclica.com/. Accessed 04 May 2013

18. S Monk, Web page of Raspberry Pi, http://www.raspberrypi.org/. Accessed 04 May 2013

doi:10.1186/1687-1499-2014-115

Cite this article as: Herrera-Quintero et al: Web service platform for automatic generation of O/D matrix. EURASIP Journal on Wireless Communications and Networking 2014 2014:115.

\section{Submit your manuscript to a SpringerOpen ${ }^{\circ}$ journal and benefit from:}

- Convenient online submission

- Rigorous peer review

- Immediate publication on acceptance

- Open access: articles freely available online

- High visibility within the field

- Retaining the copyright to your article

Submit your next manuscript at $\gg$ springeropen.com 